\title{
Space Syntax-able Attributions for Safety Consideration of Heritage Area
}

\author{
Noor Kamilah Kezuwani, Shahrul Yani Said \\ Faculty of Architecture, Planning and Surveying, Universiti Tekonologi MARA, Shah Alam, Selangor, 40000 Malaysia \\ 2017831682.kamilah@gmail.com, shahrulyani@uitm.edu.my \\ Tel of 1st Author: 60 12-232 5704
}

\begin{abstract}
Understanding crime has been in focus for a few decades. Significant research has begun to understand the relationship between spatial configuration and crime occurrence, which related back to human behaviour. In recent year, space syntax has been used as a method to analyse space and its spatial properties. Urban design researchers have employed the space syntax technique to analyse the geographic distribution of crime due to spatial and socio-demographic factors that could influence crime patterns. This paper describes how space syntax could be used to assess crime possibility in heritage areas, and the result supports the hypothesis.
\end{abstract}

Keywords: Urban planning, Crime prevention theory, Space syntax, Spatial configuration

eISSN: 2398-4287@ 2021. The Authors. Published for AMER ABRA cE-Bs by e-International Publishing House, Ltd., UK. This is an open access article under the CC BYNC-ND license (http://creativecommons.org/licenses/by-nc-nd/4.0/). Peer-review under responsibility of AMER (Association of Malaysian Environment-Behaviour Researchers), ABRA (Association of Behavioural Researchers on Asians/Africans/Arabians) and cE-Bs (Centre for Environment-Behaviour Studies), Faculty of Architecture, Planning \& Surveying, Universiti Teknologi MARA, Malaysia.

DOI: https://doi.org/10.21834/ebpj.v6iSI4.2903

\subsection{Introduction}

Maintaining public security and safety have become challenging with unprecedented growth in urbanisation, globalisation and mitigation. In the early day, the crime study focus on the justice system and policymaking; however, the rate keeps growing. These few decades, the study more focus on the cause of the crime itself in both design and social aspect (Kitchen, T., \& Schneider,2007). There is no doubt that environment and its layout have influence crime activities (Greene, 2003; Hillier \& Sahbaz, 2008; L. Nubani \& Wineman, 2008; Tavares Monteiro, 2012; Akkelies Van Nes \& López, 2010; Zaki, Abdullah, \& Ramli, 2008). Specific crime takes place in particular locations with a particular setting and attributes. By understanding the environment and its manipulation can be eliminated or reduce the crime. Environmental criminology theories explain the relationship between surrounding and behaviour, how it leads to crime. Routine activity theory explains how one's routine away from their protective environment leads them to become a potential target. Previous research on general activity theory and rational choice theory indicates the absence of a capable guardian to prevent crime will provide ample opportunity to being the target of crime.

The safety issue has been the main focus in some urban design theory (Berlusconi, 2017; Keatley, 2018; Lee, Park, \& Jung, 2016) which that crime can be reduced manipulation of urban planning and design. Crime Prevention through Environmental Design (CPTED) by C. Ray Jeffery in 1971 is influenced by theory by Jane Jacob's book in The Death and Life of American Cities in 1961 that focus on natural surveillance or 'eyes on the street'. The difference from the Defensible Spaces by Oscar Newman that publishes a year later that CPTED theory, it focuses on territoriality and hierarchy of spaces. Both ideas published about the same time, but defensible spaces are more accepted and widely used due to its direct approach to the issue. In the mid-twentieth century, the idea of sustainable start to

eISSN: 2398-4287@ 2021. The Authors. Published for AMER ABRA cE-Bs by e-International Publishing House, Ltd., UK. This is an open access article under the CC BYNC-ND license (http://creativecommons.org/licenses/by-nc-nd/4.0/). Peer-review under responsibility of AMER (Association of Malaysian Environment-Behaviour Researchers), ABRA (Association of Behavioural Researchers on Asians/Africans/Arabians) and cE-Bs (Centre for Environment-Behaviour Studies), Faculty of Architecture, Planning \& Surveying, Universiti Teknologi MARA, Malaysia.

DOI: https://doi.org/10.21834/ebpj.v6iSI4.2903 
articulated, emerge the New Urbanism that emphases of sustainability. It is a massive renewal to Jane Jacob's theory (Kitchen \& Schneider, 2007).

More recently, researchers have employed space syntax to analyse spatial configuration in and its effect on human behaviour (Hillier, 2002; Jones \& Fanek, 1997; A Van Nes, 2006; L. N. Nubani, n.d.; L. Nubani \& Wineman, 2008; A Van Nes, 2017), The research looks into how the layout of the built environment effect on the crime. This paper adds to the body of knowledge, focusing on how space syntax used in the spatial-crime study while considering the environmental criminology theories and urban design theories.

\subsection{Literature Review}

Based on the ideas that committing offence any have to influence from environment layout, some researchers have employed space syntax in their study. Most researchers how to employ space syntax shows that crime, in particular a property crime, tends to cluster in a less integrated or segregated area. One of the first space syntax researchers is Shu (1999), by looking at the spatial distribution of burglary in three different districts $A, B$ and $C$ of Town $X$ of northern Taiwan. District $A$ had the lowest density and characterised as a farming area, while District $B$ is a historical centre that now serves as the main commercial and administrative centre. Its density falls in between District $A$, and District $C$. District $C$ has the highest density and mainly serve as a residential area. A total of 121 neighbourhood within the administration are classified according to the level of income: low, middle and high. The data show from global integration in low-income and middle-income prove to be beneficial, the more global integration is safer that segregated area.

On the second phase of in the intense study, Shu focuses on District $C$ due to the highest density and the burglaries case. She looks at the type of road, road accessibility and immediate surrounding of dwelling as significant elements. The finding shows that the integrated area was safer that segregated. The resulted more pronounced in lower and middle-income area, that opposite social paradox which poverty and income level lead toward crime.

Hillier and Sahbaz (2008) in their study, stressing out that there was an open and closed solution because in crime prevention, where there two significance theories have different ideology. The first is traceable to Jane Jacobs book 'The Death and Life of the Great American Cities' suggesting permeable, open and mix land use that encourages strangers passing through beside people who occupant the place and provide more 'eyes on the street'. Oscar Newman, in Defensible Space, argues by having too many people in an area creates the opportunity for the offender. And, a single-use environment with restricted access to a stranger, these will make a constrained environment where occupant knows each other and can recognise strangers or intruders. They use a risk band analysis to conduct the study at London in four different levels; ward, output area, street segment and individual resident. Each theory aims to provide a methodology and a body of evidence to address the question. The empirical data show that certain principles in each argument foam a larger and more complex picture, which each side needs to rethink its principles. The final solution seems to be conservative in overstating and underestimate the potential and essential life outside closed-off area, while open solution been too optimistic to exposing the street to the public by not understand and link permeability with the realistic movement pattern.

Van Nes (2007) also have conducted spatial research characteristic and its relation towards the geographic distribution of residential burglaries and auto thefts at the Dutch cities Gouda and Alkmaar by use risk band analyses in the study (similar to Hillier and Sahbaz). He aims to study in macro and micro level in term of street net configuration. In the macro-level analyses, spatial measurement using space syntax were used to identify the main routes through the cities, then manually calculation central route segment depth within radius 3 . In the micro-scale analysis, research was focusing on spatial relationships between street segments and built object. The configuration of private and public spaces indicates the degree of inter-visibility from neighbouring houses is measured. The result shows a strong correlation between the dispersal of burglar and inter-visibility from the window. Hillier and Sahbaz's band analysis showed a similar effect for the street would be several building, like cul-de-sac street were more vulnerable toward crime. However, the study shows the most dominant factor variables in spatial assessment is the topological depth of street segment which related to central route system. In which it gives an indication that city movement flow shows a significant correlation with microenvironment and distribution of residential burglary and auto theft.

Nubani (2005) adopting a similar approach from other space syntax researcher by identifying geographical patterns of crime in Ypsilanti, Michigan. She looks into the influence of spatial configuration toward crime, focusing on robbery, motor vehicle theft, breaking, and robbery. Firstly, an axial map of Ypsilanti Street by the longest sight-line to use to characterise every street segment in the area manually on top of the chart using Spatialist. Later the plan will be merging in ArcGIS using "joint attribute" to overlay with hot spot mapping. Result of the analysis showed that connectivity and local integration were highly associated with crime. Contrast to previous studies; local integration has a positive correlation toward crime; the finding show street with low integration value was safer. The study shows that median income, racial composition and level of education have on significant in the study.

Not only Nubani (2005), a similar conclusion was also found in Baran, Smith and Toker (2007) while studying the relationship between spatial configuration and crime occurrence in the Town of Cary, North Carolina. The finding show that crime tends to concentrate in high global integrate area, and connectivity has no significant toward the study. When we look into land use, those areas are commercial. These show a contradict example to the eyes on the street theory where indicate the high pedestrian will lead to lower the crime occurrence. Secondly, in comparison to Jacob's idea that a various land use has a predictive effect on the crime, Baran (2007) argues that a high global integration area with land use provide more crime occurrence. The finding suggests offender in Town of Cary selects the potential target among the land parcel in term of accessibility or the overlapping of their routine activities. 


\subsection{Urban Design Theories of Crime Prevention}

The idea of how the built environment has influence crime occurrence started as early as 1961 when Jane Jacob's publish her book "The Death and Life of Great American Cities". In her book, she suggests that a crime rate was lower at a high-density street with the well-maintained environment from Jacob's theory, it opens the horizon to think the relationship between built environment and crime. Since then, theories like Crime Prevention through Environmental Design (CPTED), defensible Spaces and new urbanism have emerged and shaped the urban design theories of crime prevention.

Defensible spaces published just after year CPTED was introduced, it natural that both theories were compared. Both ideas have suggested a similar principle but with different strategist. C.Ray Jeffery is a criminologist who develops Crime Prevention through Environmental Design; his work was influence by Jane Jacob's work. Jacob suggests a vibrant and high-density environment that well maintained can possess lower crime occurrences (Dunn \& Johnstone, 2012). The street will defend by people on the road how to enjoy the activity that street offer, which in Jacob's described as putting eyes on the street. Newman's defensible space has the influence from Elizabeth Wood's work in Chicago Housing Authority and surmised by improving the neighbourhood along with increased surveillance opportunities may enhance security for citizen by boosting chance for natural social control (Andresen \& Malleson, 2015; Dunn \& Johnstone, 2012; Faria, Ogura, \& Sachsida, 2013; Mawby, 2017).

Later in the mid-twentieth century, New Urbanism starts to articulate as the effect of growth idea of sustainable development, and much thinking were underpinning to Jane Jacob's idea. Plater Zyberk, expected in new urbanism said, "We believe that the physical structure of our environment can be managed and that controlling it is the key to solving numerous problems confronting government today - traffic congestion, pollution, financial depletion, social isolation and yes, even crime (Schneider \& Kitchen, 2002, 2007). Because of the root of CPTED and New Urbanism is same, they offer a similar solution. However, New Urbanism working toward making sustainability and pedestrian-oriented place.

Due to the nature of the place different from one another, crime prevention always provides a clear answer (Hillier \& Sahbaz, 2008). Crime prevention may work efficiently and effectively in one neighbourhood but may fail in other neighbourhood even there was adjacent. Therefore, a study is needed before any theory can be adopted as a crime prevention strategist.

Each theory has its own principle with a different approach of a strategist; however, some of the principles from different theory can be categories into one group. Therefore, the elements of the same categories principle can be grouped together. For example, under closed observation, defensible spaces and CPTED have similar principle but have a different approach. Defensible spaces also stressed on the physical design and were try avoiding strangers and outsider, while CPTED were focus on creating more vibrant to put more eyes on the street. For that reason, closed observation will have attributes from both defensible spaces and CPTED theories (Table 1).

Table 1: List of principle in in urban design theories of crime prevention correlation and attribution

\begin{tabular}{|l|l|l|l|}
\cline { 2 - 4 } \multicolumn{1}{l|}{} & \multicolumn{1}{c|}{ Defensible Spaces } & \multicolumn{1}{c|}{ CPTED } & \multicolumn{1}{c|}{ New Urbanism } \\
\hline Closed observation & Surveillance & $\begin{array}{l}\text { Natural } \\
\text { surveillance }\end{array}$ & \\
\hline Dermeability & & $\begin{array}{l}\text { Access control } \\
\text { and Legibility }\end{array}$ & $\begin{array}{l}\text { 1. Walkability } \\
\text { 2. Connectivity }\end{array}$ \\
\hline Impression of space & Territoriality & $\begin{array}{l}\text { Territorial } \\
\text { reinforcement }\end{array}$ & \\
\hline Function of space & mage and Milieu & $\begin{array}{l}\text { Quality Architecture \& Urban } \\
\text { Design }\end{array}$ \\
\hline
\end{tabular}

\begin{tabular}{|l|}
\hline \multicolumn{1}{|c|}{ ATTRIBUTION } \\
\hline Inter-visibility opening \\
Entrance and building \\
orientation \\
Unit of building in block \\
\hline Street constitutedness/adjacency \\
Street accessibility \\
Street form \\
\hline Public space and private space \\
Barrier; physical or symbolic \\
\hline - Cleanses \\
- Lighting \\
- Sense of vandalism \\
\hline - Space function \\
- Abandoned building \\
\hline
\end{tabular}

\subsection{Methodology}

This article reviews the research carried out on urban design theories in relation to safety of places and its suitability to be implemented in heritage areas. By reviewing past research, space syntax is a reliable to quantify spatial element that have significantly correlate with movement pattern either by pedestrian or vehicle (Al Sayed et al., 2014; Brown, 1997; Hillier, 2012) in the urban space and building. Space syntax provides set of data which explain the connection social information and spatial element. It uncovers structure and hidden pattern within one's space. This crime study context, pattern theory of crime explain who movement can be associated with crime (Andresen, Brantingham, \& Kinney, 2010).

The study identifies the principle of urban theories and sets of attributes that govern the theories. These attributes then, correlated with space syntax elements that will produce a set of new attributes suitable to be use in assessing safety of heritage areas.

The aim for this study is to identify factor in urban design theories and space syntax that affect crime in heritage areas and can be achieve by synthesizing previous research for crime using space syntax as spatial analysis and adaptability of listed attribution in urban design towards it. 
Urban conservation differs from urban design because of the consideration of heritage significances of the place as the major influence of any conservation program. The correlation in Table 1 signifies elements in heritage areas that could be considered in space syntax analysis.

\subsection{Finding and Discussion}

Analysis of spatial properties of heritage areas can be done in space syntax using method of integration, choice, connectivity and depth. It describes society logic in spatial system, how spaces are put together or the configuration of space, relates directly with how people perceive. It will provide pattern and empirical data respective to method chosen. Five elements of space syntax are considered importance in identifying CPTED attribution in heritage areas. The elements are integration, connectivity, choice, depth and intelligibility.

Integration can be divided into three measurements; local integration, global integration and normalised integration. Local integration was calculate using radius-3 and radius-5, which the axial line depth is 3 and 5 and use to interpreted how people how familiar with the layout move, usually the local occupant, while global integration calculate using radius-7. Global integration will show the movement in and out of there area usually been use to see the general movement of stranger. Normalized Integration value can be used as measure to compare the status of streets in different cities. Another important measurement in space syntax is connectivity. These refer to connection the number of axial line that intersects with another axial line. It is considering a local measurement is it can directly observe from a space.

Connectivity is defined by number of nodes that directly connected to street segment (Attila, 2007; Lam, 2008). It shows the local characteristic of the neighbourhood. Both integration and connectivity were basic measurement for space syntax. In heritage neighbourhood connectivity often reflected through changes in road pattern and the morphology of the place. The growth of a town can be seen through the space syntax assessment of the morphological changes that could be identified using connectivity attributes. Best connected spaces reflect easy access.

Besides that, choice is an attributes that describe "Throughmovent" that represent choice of path to the segment of the street. It shows how much movement is likely trip to pass each segment of street to designated street segment. This attribute is important as it describe the movement pattern of people. CPTED consideration is important while locating the public and private areas; accessible or non-accessible to a group of people.

Meanwhile, another important attribute is intelligibility. The way the layout or the design of street can be understood by users. Heritage areas often grow according to the needs of the users. Spaces are defined through what people perceived and how they use the space. This also reflect the socio-cultural activities of the place. A good CPTED programme should consider the demarcation of private and public areas to ensure the safety of the occupants.

A correlation of space syntax elements and urban theories of safety and hot spot analysis using ArcGIS will provide an insightful findings of the condition of the assessed heritage areas. The correlation analysis provides perimeter of heritage area with crime occurrences, and identify measures to lower the crime rate by introducing CPTED elements to the design of the place (Fig 1).

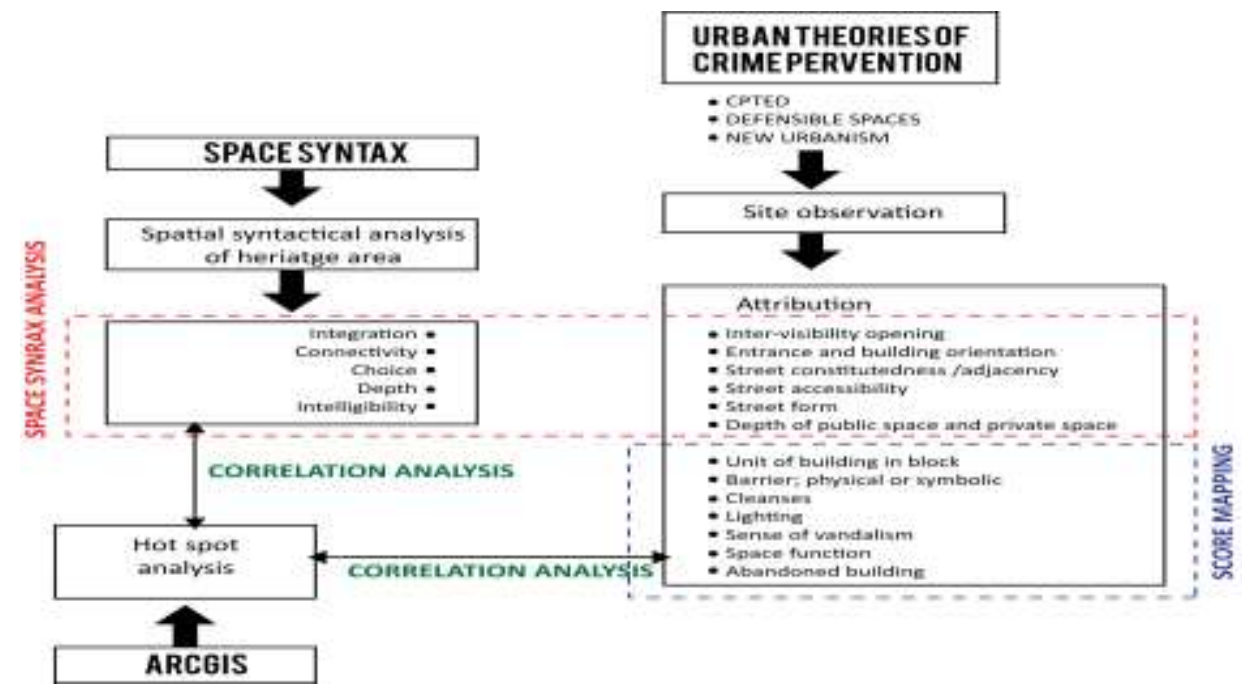

Fig 1: Adaptability of urban design crime prevention theory to space syntax measurement

\subsection{Conclusion}

Space syntax is a method that focuses on people cognition in a place regardless of what they have seen or been seen by others. When it related to the spatial-crime study, space syntax analysis depends on it value as surveillance as deterrence tool toward offender motivation to committing the crime. The result for previous studies can be summaries into three general conclusions, (i) quieter area or 
in space syntax language is segregated area were more prone to crime rather than integrated area due to lack of the movement; (ii) high global integration that indicated a clear pattern movement in and (iii) out of the area is an effective way to control and prevent crime.

If compared to urban design theories of crime prevention, especially on defensible spaces and CPTED, some of the result provide a clear cut evident were the most working crime prevention strategist work for the particular area. Previous research using space syntax space anonymity and isolation as an element that provoke criminal motivation which is clear opposite to Newman's theory of defensible spaces. The result also support the ideas of Jacob's philosophy is 'Life and death of American Cities', CPTED and new urbanist design approach that believe free flow movement and mixing stranger is therapeutic relative to crime prevention.

On the other hand, some studies show a strong empirical data that support increasing on pedestrian will provoke offender's motivation to commit a crime while connected and simple urban layout provide a predictable and easy escape route to the offender. These indicated that the area was arguably safer when been sheltered from strangers or outsider, which showed territorial reinforcement and proper placement of land use that been emphases by CPTED and defensible spaces.

Although there was a mixed result achieved by using space syntax, it is the result of the unique character of people that inhabit the area were different from each other and such crime were commit locally. However, it proves that space syntax is a useful and reliable tool for spatial-crime study. It appears to be a promising new tool to examine implications of spatial configuration toward crime, and design options to prevent the crime.

\section{Acknowledgement}

This research is carried out as part of 'Developing A Space Syntax Embedded Environmental Design Model (EDM) For A Safe Heritage Area (SHEA)' 600-IRMI/FRGS 5/3 (026/2017) sponsored by the Ministry of Education Malaysia.

\section{References}

Al Sayed, K., Turner, A., Hillier, B., lida, S., Penn, A., Griffiths, S., ... Hanna, S. (2014). SPACE SYNTAX METHODOLOGY.

Andresen, M. A., Brantingham, P. J., \& Kinney, J. B. (2010). Classics in Environmental criminology.

Andresen, M. A., \& Malleson, N. (2015). Intra-week spatial-temporal patterns of crime. Crime Science, 4(1). https://doi.org/10.1186/s40163-015-0024-7

Attila, F. (2007). SPACE SYNTAX IN URBAN RESEARCH.

Berlusconi, G. (2017). Social network analysis and crime prevention. Crime Prevention in the 21st Century: Insightful Approaches for Crime Prevention Initiatives https://doi.org/10.1007/978-3-319-27793-6_10

Brown, F. E. (1997). Space is the machine. Design Studies. https://doi.org/10.1016/S0142-694X(97)89854-7

Dunn, S., \& Johnstone, L. (2012). PIA Submission: Inquiry into Crime Prevention through Environmental Design in Victoria. Retrieved from www.planning.org.au/vic

Faria, J. R., Ogura, L. M., \& Sachsida, A. (2013). Crime in a planned city: The case of Brasilia. The International Journal Of Urban Policy and Planning, $32,80-87$. https://doi.org/10.1016/j.cities.2013.03.002

Greene, M. (2003). URBAN SAFETY IN RESIDENTIAL AREAS: Spatial variables in crime and feeling of (in)security, 1-24.

Hillier, B. (2002). CAN S TREETS BE MAD E S AFE? Retrieved from http://www.spacesyntaxlaboratory.org

Hillier, B. (2012). Studying cities to learn about minds: Some possible implications of space syntax for spatial cognition. Environment and Planning B: Planning and Design https://doi.org/10.1068/b34047t

Hillier, B., \& Sahbaz, O. (2008). High Resolution Analysis of Crime Patterns in Urban Street Networks: an initial statistical sketch from an ongoing study of a London borough, $452-477$

Jones, M. A., \& Fanek, M. F. (1997). CRIME IN THE URBAN ENVIRONMENT.

Keatley, D. (2018). PATHWAYS An Introduction to Analysis. Springer International Publishing AG. https://doi.org/https://doi.org/10.1007/978-3-319-75226-6 Lam, K. S. (2008). An introduction of space syntax.

Lee, J. S., Park, S., \& Jung, S. (2016). Effect of crime prevention through environmental design (CPTED) measures on active living and fear of crime. Sustainability (Switzerland). https://doi.org/10.3390/su8090872

Mawby, R. I. (2017). Oxford Research Encyclopedia of Criminology Defensible Space Defensible Space: From Oscar Newman to Crime Prevention through Environmental, (2018), 1-30. https://doi.org/10.1093/acrefore/9780190264079.013.6

Nes, A Van. (2006). The burglar as a space explorer in his own neighborhood. WIT Transactions on Ecology and the Environment, 93, 671-680. https://doi.org/10.2495/SC060641

Nubani, L. N. (n.d.). USING SPACE SYNTAX SOFTWARE IN EXPLAINING CRIME, 383-395.

Nubani, L., \& Wineman, J. (2008). The Role of Space Syntax in Identifying the Relationship Between Space and Crime, 414-422. 
Schneider, R. H., \& Kitchen, T. (2002). Reviews Planning for Crime Prevention : A TransAtlantic Perspective.

Schneider, R. H., \& Kitchen, T. (2007). Crime Prevention and the Built Environment.

Tavares Monteiro, L. (2012). The Valley of Fear - The morphology of crime , a case study in João Pessoa , Paraíba , Brasil, 1-15.

Van Nes, Akkelies. (2017). Spatial Improvement Strategies for Deprived Neighbourhoods.

Van Nes, Akkelies, \& López, M. J. J. (2010). Macro and Micro Scale Spatial Variables and the Distribution of Residential Burglaries and Theft from Cars An investigation of space and crime in the Dutch cities of Alkmaar and Gouda, 296-314. Retrieved from http://www.journalofspacesyntax.org/

Zaki, S. A., Abdullah, J., \& Ramli, N. S. (2008). URBAN SPACE AND ITS INFLUENCE ON CRIME. Built Environment Journal, 5(2), $24-31$. 